АНДРЮШИНА Евгения Владимировна - кандидат политических наук, доцент кафедры политического анализа факультета государственного управления Московского государственного университета им. М.В. Ломоносова (119991, Россия, г. Москва, Ломоносовский пр-кт, 27, корп.4; Andryushina@spa.msu.ru)

ЛУЦЕНКО Никита Олегович - кандидат политических наук, старший преподаватель кафедры международной коммуникации факультета мировой политики Московского государственного университета им. М.В. Ломоносова (119991, Россия, г. Москва, ул. Ленинские Горы, 1, стр. 51; Lutsenkono_msu@mail.ru)

\title{
ГОСУДАРСТВЕННАЯ ПОЛИТИКА ПО СТИМУЛИРОВАНИЮ РОЖДАЕМОСТИ: ЗАРУБЕЖНЫЕ ПРАКТИКИ И УРОКИ ДЛЯ СОВРЕМЕННОЙ РОССИИ
}

Аннотация. В предлагаемой статье представлен обзор современных мер государственной политики в области поддержки семей с детьми, демографической политики ряда зарубежных стран. Авторы дают оценку эффективности их реализации, а также рассматривают возможность учета зарубежного опыта при имплементации семейной и молодежной политики современным российским государством.

Ключевые слова: государственная семейная политика, демографическая политика, молодежная политика, эффективность государственной политики, государственное регулирование репродуктивного поведения, национальный проект «Демография»

\begin{abstract}
Современное российское государство в течение последних лет предпринимает активные стратегические и тактические шаги по выработке и реализации мероприятий в области демографии, о чем свидетельствует повышенное внимание к данной проблеме со стороны высших политико-административных центров. Демонстрацией подобного акцента российской власти на вопросах улучшения демографической ситуации является придание вопросам увеличения рождаемости, поддержки семей с детьми, взрослого поколения, ведения здорового образа жизни статуса государственных приоритетов в рамках национального проекта «Демография» 1.

В целом следует отметить, что демографические проблемы России не являются уникальными; большинство стран западного мира (преимущественно речь идет о странах - членах ОЭСР, ЕС) также уже не первое десятилетие находятся в процессе поиска способов улучшения демографической ситуации на фоне старения населения [Guzzo, Hayford, Lang 2019: 134-135], изменения приоритетов граждан в вопросе создания семьи и желания иметь детей и т.д., включая распространение в некоторых западных странах однополых браков [Regnerus 2012] и проблем наличия и воспитания детей в таких семьях [Musick 2014].

Несмотря на наличие универсальных ценностей, таких как социальные гарантии, права и защита детей, декларируемых в основополагающих документах ООН и его подразделений, каждое государство предлагает собственные методы поддержки репродуктивного поведения и семей с детьми, специфицирует объект поддержки (помощь неполным и многодетным семьям,
\end{abstract}

\footnotetext{
${ }^{1}$ Национальный проект «Демография». Доступ: https://rosmintrud.ru/ministry/programms/ demography (проверено 19.08.2020).
} 
семьям с определенным уровнем достатка), имплементирует конкретные механизмы (в виде денежных трансфертов и субсидий на выплату пособий по рождению ребенка, выплат за период ухода за ребенком, включая выплаты за 2-3 месяца до рождения; субсидирования и частичного финансирования дошкольного образования, мероприятий по поддержке молодежи, оплате жилья; использования инструментов системы налогообложения в форме налоговых вычетов, уменьшения налоговых окладов вПлоть до отмены уплаты налогов).

Важнейшей мерой поддержки семей с детьми является систематическая выплата пособий на детей, которая по-разному реализуется в странах ОЭСР. Так, практически все государства стимулируют появление хотя бы одного ребенка в семье с помощью финансовых пособий (за исключением Германии, Франции, Греции), некоторые же страны поощряют многодетные семьи (Германия, Ирландия, Франция, Люксембург, Швеция) [Журавлева 2016].

Эффективность мер стимулирования рождаемости и государственной политики в сфере поддержки семей с детьми варьируется от страны к стране в зависимости от разных факторов - от исторических и социокультурных аспектов семейной политики и характеристики семейных ценностей в различных обществах до уровня социально-экономического развития и благополучия отдельных стран. Так, наиболее успешными государствами в данном контексте можно считать страны Северной Европы. В Швеции, к примеру, государство поддерживает семьи с числом детей от 4 чел. и больше (размер выплат на ребенка составляет $615 €$ при 4 детях, $858 €-$ при 5 и $1101 €-$ при 6), в соседней Норвегии за каждого ребенка семья получает $129 €$ и дополнительные доплаты за проживание в северных регионах. Более того, в Норвегии «матери, ходившие на работу до рождения ребенка, в течение последующих сорока двух недель получают полное возмещение зарплаты. В качестве альтернативы им предлагают $80 \%$ от зарплаты, но на протяжении года»1. В Финляндии матери/ отцы, находящиеся в отпуске по уходу за новорожденным ребенком, в течение 9 месяцев также получают около $80 \%$ заработной платы. После этого они имеют право на отпуск по уходу за ребенком до 3 лет при фиксированной сумме отпускных по уходу за ребенком (около 600 евро в месяц в зависимости от региона).

Разброс размера пособия на ребенка в возрасте от 3 до 12 лет в странах ОЭСР также велик - от $1 \%$ средней заработной платы в Испании и Исландии до 8-9\% в Австралии и Словении.

Специфический набор мер семейной политики и политики стимулирования рождаемости предопределяет желаемый для государства тип семьи (кто именно ухаживает за ребенком в послеродовой период, сколько детей в семье). Так, для Великобритании и Исландии характерна малодетная семья (12 ребенка), в то время как для североевропейских государств, Франции - 56 детей [Журавлева 2016].

Существенные коррективы в вопросы оперативных мер поддержки семей с детьми большинства стран внесла пандемия коронавируса. Главным образом данная помощь выражается в мерах финансовой поддержки и является частью общего плана мероприятий поддержки всех слоев населения, пострадавших от эпидемии. Так, к примеру, в Канаде единовременные выплаты на детей до 12 лет осуществляются в размере 200 \$ и на детей до 21 года с особыми нуж-

${ }^{1}$ Седракян Р. Мировой опыт демографического регулирования. - Известия. 14.02.2017. Доступ: https://iz.ru/news/664692 (проверено 19.08.2020). 
дами - в размере $250 \$ 1$; в США выплаты на детей до 16 лет составляют $500 \$ 2$. Беспрецедентна для современной социальной политики России и инициатива по выплатам детям до 3 лет пособий на протяжении 3 месяцев, а также единовременное пособие всем российским детям в возрасте от 3 до 16 лет безо всяких условий в размере 10000 руб.

Другое направление помощи - предоставление субсидий на вынужденный отпуск по уходу за детьми в связи с закрытием школ (Франция, Япония, Корея) ${ }^{3}$.

Критериями для определения целевых групп, нуждающихся в поддержке, для государственных органов являются доход семьи, число детей в семье, а также, как уже было указано, бюджетные возможности государства. В целом меры по поддержке семей и стимулированию рождаемости сводятся именно к финансовому стимулированию. Безусловно, именно данная практика доказала и доказывает свою эффективность. Так, всеобщее детское пособие в Испании с 2007 г. размером в 2500 евро способствовало увеличению рождаемости на 6\% [González 2013: 172]; подобная ситуация характерна и для Израиля [Cohen, Dehejia, Romanov 2013: 11-15].

Современные российские практики реализации демографической политики также сфокусированы на вопросах финансовой поддержки семей с детьми: это реализация программы по выплатам материнского капитала (включая распространение программы на рождение первого ребенка с января 2020), субсидии, пособия, единовременные выплаты на детей, социальная помощь, предоставление многодетным семьям жилья, земли (на определенных условиях), скидки на определенные услуги/товары, бесплатный проезд на отдельных видах общественного транспорта, бесплатное посещение ряда культурных учреждений, предоставление льготных путевок в детские лагеря и др. Как правило, данные меры касаются многодетных семей. К дополнительным - организационным мероприятиям поддержки семей с детьми в РФ можно отнести меры по созданию условий для работы матерей с маленькими детьми и меры по повышению доступности дошкольного образования детей в возрасте до 3 лет. Важнейшим направлением государственной политики по стимулированию рождаемости и поддержке семей с детьми является пропаганда института семьи с детьми, повышение престижа статуса отцовства и материнства. Как мы уже отмечали, к рекомендациям по повышению эффективности государственной политики по стимулированию рождаемости можно отнести расширение типов семей (не только многодетные, но и одно- и двухдетные семьи), на которые будет распространяться львиная доля мер господдержки в виде льгот и выплат ${ }^{4}$ с ущщественное увеличение меры финансовой поддержки матерей/отцов, находящих в отпуске по уходу за малолетним ребенком; обеспечение детей доступными яслями и детскими садами [Андрюшина, Панова 2019]. Одним из последних стратегических мотиваторов к стимулированию рождаемости в современной России является внесение поправки в Конституцию РФ о поддержке детей и

1 https://www.ontario.ca/page/get-support-families (accessed 19.08.2020).

2 F.A.Q. on Stimulus Checks, Unemployment and the Coronavirus Plan. - The New York Times. 24.07.2020. URL: https://www.nytimes.com/article/coronavirus-stimulus-package-questionsanswers.html (accessed 19.08.2020).

3 Меры бюджетной политики для защиты населения во время вспышки коронавируса. - Официальный сайт Международного валютного фонда. Доступ: https://www.imf.org/ru/ News/Articles/2020/03/06/fiscal-policies-to-protect-people-during-the-coronavirus-outbreak (проверено 19.08.2020).

${ }^{4}$ Следует отметить, что государство частично уже начало реализацию данной инициативы через предоставление права на получение материнского капитала с рождением первенца. 
института семьи в целом как базовой ценности российского общества и государства.

И все же, давая оценку эффективности мер государственной политики в сфере стимулирования рождаемости, следует констатировать сохранение большинства проблемных зон. Представляется, что объективным неоспоримым критерием для оценки эффективности является число детей на одну женщину (в возрасте от 15 до 44 лет). В странах ЕС он по-прежнему остается довольно низким, стран с превышением показателя рождаемости больше 2 детей практически нет, и практически во всех странах ОЭСР продолжается тенденция к сокращению данного индекса.

Самый высокий индекс рождаемости продемонстрировала Ирландия $(1,98)$, низкий - Молдова $(1,23)^{1}$. В этом смысле современная Россия с коэффициентом 1,751 также может быть отнесена к группе европейских стран с не самым маленьким показателем рождаемости!

Страны Северной Европы и Франция имеют показатель, близкий к 2. Коэффициент рождаемости во Франции составляет 1,852 , и в последние несколько лет он неуклонно снижается. Когда-то Франция была известна и гордилась тем, что имеет самые высокие показатели рождаемости в Европе, а снижение коэффициента рождаемости вызывает во Франции обеспокоенность. Поэтому в стране приоритетными являются стимулы к рождению детей, такие как субсидии на детский сад, специальные скидки и денежные пособия семьям ${ }^{2}$.

Норвегия - еще одна европейская страна, в которой наблюдается снижение коэффициента рождаемости, который на данный момент составляет 1,68. Важным фактором снижения рождаемости в Норвегии является увеличение возраста матерей-новичков, который в среднем составляет 29,5 лет. Кроме того, здесь все меньше больших семей. Это чревато для Норвегии осложнениями в долгосрочной перспективе, поскольку будет меньше людей трудоспособного возраста, которые будут платить налоги, что нанесет ущерб финансированию системы социального обеспечения. Норвегия изучает варианты поощрения родов, например выплату матери пенсионных накоплений за каждого родившегося ребенка 3 .

В Италии снижение уровня рождаемости вызывает серьезное беспокойство со стороны государства, поскольку в настоящее время коэффициент рождаемости составляет лишь 1,33. Средний возраст «начинающих» мам в Италии - 31 год, самый высокий в Европе. Основная причина того, что женщины в Италии не имеют детей, заключается в том, что они финансово не готовы растить ребенка, а правительство не помогает оплачивать расходы по уходу за детьми. Самый высокий уровень рождаемости в Европе, как было отмечено, - в Ирландии. Однако этот показатель все еще ниже уровня воспроизводства населения в 2,1. Одной из причин снижения коэффициента рождаемости в Ирландии является средний возраст матерей-новичков, который составляет 30,3 года. Двумя возможными факторами, способствующими снижению уровня рождаемости в Ирландии, являются отсутствие гибких вариантов работы и высокие расходы по уходу за ребенком. Эти факторы заставляют женщин жертвовать семьей ради своей карьеры ${ }^{4}$.

Как следует из приведенных примеров, главную причину низкого коэф-

1 Total Fertility Rate 2020. - World Population Review. URL: https://worldpopulationreview. com/countries/total-fertility-rate/ (accessed 19.08.2020).

2 Ibid.

3 Ibid.

4 Ibid. 
фициента рождаемости и, как следствие, неэффективности политики по стимулированию рождаемости - повышение возраста женщины, рожающей первого ребенка, можно экстраполировать на большинство западных стран (государства континентальной Европы и страны англосаксонской семьи).

Таким образом, преобладание финансовых и организационных инструментов стимулирования рождаемости является недостаточным при выработке и реализации государственной семейной и демографической политики современных западных стран. Представляется, что целенаправленные усилия должны быть направлены на адресную работу с молодежью (особенно с женщинами до 20-25 лет) как ключевой социальной группой. Опыт стран ЕС демонстрирует провалы в политике стимулирования молодых женщин к рождению детей.

В данном контексте необходимо отметить, что и современную российскую политику в этой сфере следует дополнить рядом стратегических мероприятий в области работы именно с молодежью, в т.ч. студенческой.

Как творческий коллектив авторов МГУ имени М.В. Ломоносова, занимающихся проблемами молодежной и семейной политики, мы неоднократно указывали на несовпадение интересов молодых россиян и приоритетных направлений проводимой государством молодежной и семейной политики [Андрюшина, Панова 2017]. Современная российская молодежь в вопросе обеспечения своей семьи склонна полагаться не на помощь государства или родителей, а на свои силы. Если же говорить о той помощи, которую российское студенчество все же ожидает от государственных структур, то это помощь в обеспечении жильем. Более того, препятствиями для появления детей в российской молодой семье, помимо нерешенного жилищного вопроса, является нацеленность на обретение стабильного финансового дохода [Андрюшина, Григорьева, Панова 2019: 255]. К тому же стабильно наблюдаемое характерное для западного мира стран увеличение возраста рождения первого ребенка и у россиян формирует риск негативного решения вопроса о появлении второго и последующего ребенка в молодой семье. Интересным результатом исследования настроений российской студенческой молодежи относительно создания семьи и рождения детей является и психологическая неготовность.

Таким образом, как для российской практики государственного управления, так и для стран ОЭСР следует отметить необходимость расширения мер финансово-организационного стимулирования, в первую очередь молодых людей, к деторождению, использования инновационных кредитно-финансовых инструментов стимулирования репродуктивного поведения, включая предоставление беспроцентной/сниженной ипотеки, повышенных субсидий при рождении ребенка и выплаты во время ухода за детьми, а также активной пропаганды традиционных семейных ценностей, проведения адресной психологической работы с молодежью с использованием как традиционных, так и современных агентов социализации.

\section{Список литературы}

Андрюшина Е., Панова Е. 2017. Современная российская государственная молодежная политика: эволюция, основные направления, практики. - Власть. T. 25. № 7. С. 60-65.

Андрюшина Е., Панова Е. 2019. Государственная политика по стимулированию рождаемости и поддержки семей с детьми: практика современной России. - Власть. Т. 27. № 5. С. 105-111.

Андрюшина Е. В., Григорьева Н. С., Панова Е.А. 2019. Семейные стратегии современной российской студенческой молодежи (результаты компаратив- 
ного анализа данных опроса за 2008 и 2019 гг.) - Государственное управление. Электронный вестник. Вып. № 77. Декабрь. С. 246-273.

Журавлева Л. 2016. Анализ зарубежной практики социальной поддержки семей с детьми в странах ОЭСР. - Проблемы современной науки и образования. № 16(58). C. 51-55.

Cohen A., Dehejia R., Romanov D. 2013. Financial Incentives and Fertility. Review of Economics and Statistics. Vol. 95. Is. 1. P. 1-20.

González L. 2013. The Effect of a Universal Child Benefit on Conceptions, Abortions, and Early Maternal Labor Supply. - American Economic Journal: Economic Policy. Vol. 5. Is. 3. P. 160-188.

Guzzo K., Hayford S., Lang V. 2019. Adolescent Fertility Attitudes and Childbearing in Early Adulthood. - Population Research and Policy Review. Vol. 38. Is. 1. P. 125152.

Musick M.A. 2014. A Review of Methodological and Ethical Issues Surrounding the New Family Structures Study. URL: https://ru.scribd.com/document/260747196/ Musick-s-report\#scribd+review (accessed 19.08.2020).

Regnerus M. 2012. How Different Are the Adult Children of Parents Who Have Same-Sex Relationships? Findings from the New Family Structures Study. -Social Science Research. Vol. 41. Is. 4. P. 752-770.

ANDRYUSHINA Eugenia Vladimirovna, Cand.Sci. (Pol.Sci.), Associate Professor of the Chair of the Political Analysis, School of Public Administration, Lomonosov Moscow State University (bld. 4, 27 Lomonosovsky Ave, Moscow, Russia, 119991; Andryushina@spa.msu.ru)

LUTSENKO Nikita Olegovich, Cand.Sci. (Pol.Sci.), Senior Lecturer of the Chair of International Communication, School of World Politics, Lomonosov Moscow State University (bld. 51, 1 Leninskie Gory St, Moscow, Russia, 119991; Lutsenkono_msu@mail.ru)

\section{STATE POLICY ON STIMULATING THE BIRTH RATE: ITS FOREIGN PRACTICES AND LESSONS FOR MODERN RUSSIA}

\footnotetext{
Abstract. The article provides an overview of current state policy measures in the field of supporting families with children, the demographic policy of a number of foreign countries, evaluates the effectiveness of their implementation, and considers the possibility of taking into account foreign experience in the implementation of family and youth policy by the modern Russian state.

Keywords: state family policy, population policy, youth policy, effectiveness of state policy, state regulation of reproductive behavior, national project «Demography»
} 